\title{
A Review of the Potential Impacts of Wind Turbine Noise in the Australian Context
}

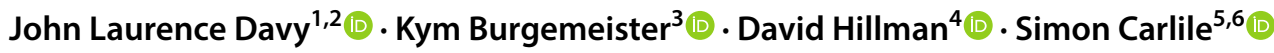

Received: 20 January 2020 / Accepted: 18 June 2020 / Published online: 27 June 2020

(c) The Author(s) 2020, corrected publication 2020

\begin{abstract}
This manuscript describes a range of technical deliberations undertaken by the authors during their work as members of the Australian Government's Independent Scientific Committee on Wind Turbines. Central to these deliberations was the requirement upon the committee to improve understanding and monitoring of the potential impacts of sound from wind turbines (including low frequency and infrasound) on health and the environment. The paper examines existing wind turbine sound limits, possible perceptual and physiological effects of wind turbine noise, aspects of the effects of wind turbine sound on sleep health and quality of life, low-frequency noise limits, the concept of annoyance including alternative causes of it and the potential for it to be affected by low-frequency noise, the influence of amplitude modulation and tonality, sound measurement and analysis and management strategies. In so doing it provides an objective basis for harmonisation across Australia of provisions for siting and monitoring of wind turbines, which currently vary from state to state, contributing to contention and potential inequities between Australians, depending on their place of residence.
\end{abstract}

Keywords Wind turbines $\cdot$ Wind farms $\cdot$ Noise $\cdot$ Annoyance $\cdot$ Health $\cdot$ Sleep

\section{Introduction}

John Laurence Davy

johnldavy@gmail.com

Kym Burgemeister

kym.burg@arup.com

David Hillman

hillo@it.net.au

Simon Carlile

carlile.simon@gmail.com

1 Royal Melbourne Institute of Technology (RMIT) University, GPO Box 2476, Melbourne, VIC 3001, Australia

2 Infrastructure Technologies, CSIRO, Private Bag 10, Clayton South, VIC 3169, Australia

3 Arup, Sky Park, One Melbourne Quarter, 699 Collins Street, Docklands, VIC 3008, Australia

4 Centre for Sleep Science, University of Western Australia, Crawley, WA 6009, Australia

5 Faculty of Medicine, University of Sydney, Camperdown, Australia

6 [X] The Moonshot Factory, Mountain View, CA 94043, USA
While renewable energy from wind turbines can have a positive environmental impact, wind turbines can also be visually imposing and are a source of audible sound and infrasound. If turbines are placed near to where people live, the wind turbine sound can potentially be loud enough to be a source of disturbance, potentially adversely affecting wakeful activities and/or sleep with resulting irritability, negativity and cognitive disturbance. It is held by some people that the audible sound and infrasound may also have more specific effects on health and well-being, including potential effects on non-auditory function of the inner ear [1]. Furthermore, the visual impact of wind turbines may cause individual concern, both in terms of their appearance and, in some cases, shadow flicker. Added to these concerns, individuals may develop negative perceptions regarding a perceived lack of fairness in planning decisions regarding siting of turbines in proximity to their dwellings. These negative reactions to wind turbine presence have been encapsulated in concept of 'annoyance' [2]. Thus, there is a logical basis for now deriving a wind turbine sound limit based on limiting annoyance.

In order to manage potential impacts from wind turbine sound, governments and regulators have established wind 
turbine sound limits that place an upper limit on the sound level that wind farms can generate and effectively place a limit on how close wind turbines can be placed to dwellings and population centres. There is some disparity in approach to this issue and this manuscript describes deliberations by the Australian Government's Independent Scientific Committee on Wind Turbines ('the committee') aimed at optimising the approach to determining their minimum distance from noise-sensitive receivers and their management. It examines aspects of the effects on sleep health and quality of life, low-frequency noise limits, alternative causes of annoyance, annoyance attributed to low-frequency noise, management strategies, amplitude modulation, measurement of wind farm tonality, wind farm sound measurement and analysis, and the statistical power of wind turbine noise studies.

The purpose of publishing these deliberations is, by making them available to technical experts for their consideration and feedback, to facilitate and promote harmonisation across Australian states of the provisions for siting and monitoring of wind turbines. This manuscript sits alongside reports from the committee of a less technical nature, including its reports to parliament and fact sheets it intends to make available on its website.

\section{Wind Turbine Sound Limits}

Committee members recently undertook a detailed review of the existing wind turbine sound limits in Australian states and several other countries with similar constraints, how these were established and a method that could facilitate their harmonisation [3]. It was found that most existing wind farm sound limits appear to have been adopted to avoid sleep disturbance but were developed using data derived from sound sources other than wind turbines. This seems to have been a reasonable approach at the time of their adoption because of the paucity of other suitable data. More recently, the concept of 'annoyance' has been used to encapsulate negative reactions to wind turbine sound. Given that many studies have now demonstrated a significant relationship between annoyance and wind turbine sound level, regardless of whether sound was the major source of the annoyance, there is a logical basis for now deriving a wind turbine sound limit based on annoyance.

The committee's analysis suggests that an appropriate noise limit to ensure that no more than $10 \%$ of the population are 'highly annoyed' when exposed to wind farm noise is between 34 and $40 \mathrm{~dB} L_{\text {Aeq (10 min) }}$ outside the residence, with a mean value of $37 \mathrm{~dB} L_{\text {Aeq (10 min) }}$ [3]. The cut-off of $10 \%$ is somewhat arbitrary and itself could be a subject of informed debate. The corresponding measurement limits in $L_{\mathrm{A} 90(10 \mathrm{~min})}$ are between 1.5 and $2.5 \mathrm{~dB}$ lower with $2 \mathrm{~dB}$ lower being a good practical value [4]. These values are similar to the lower maximum design limits already adopted, or proposed for use in Australia of 35, 37 and $40 \mathrm{~dB} L_{\text {Aeq (10 min). }}$. Thus, this study provides a method for harmonisation of future wind farm sound limits in Australia based on direct assessments of human response to wind farm sound. It should be noted that all sound pressure levels in this paper are $\mathrm{A}$-weighted and given as $\mathrm{dB}(\mathrm{A})$ unless otherwise stated.

The World Health Organisation (WHO) [5] released Environmental Noise Guidelines for the European Region in 2018. This publication conditionally recommends reducing outdoor noise levels produced by wind turbines to which people are exposed to below an $L_{\mathrm{den}}$ of $45 \mathrm{~dB}(\mathrm{~A})$. This is based on four studies which show that $10 \%$ of the population were highly annoyed with wind turbines when exposed to outdoor wind turbine noise levels of $L_{\mathrm{den}}$ equals $45 \mathrm{~dB}(\mathrm{~A})$. Like the National Health and Medical Research Council (NHMRC) [6], WHO rated the evidence used to determine this wind turbine noise limit as being of low quality and that is the reason why the recommendation is conditional. An $L_{\mathrm{den}}$ of $45 \mathrm{~dB}(\mathrm{~A})$ is equivalent to an $L_{\mathrm{Aeq}}$ of $38.6 \mathrm{~dB}(\mathrm{~A})$. This conversion assumes that the distribution of wind turbine sound levels is the same during the day, evening and night [7]. This is close to the wind turbine noise limit of $L_{\mathrm{Aeq}}$ of $37 \mathrm{~dB}(\mathrm{~A})$ determined by the committee [3] using the same requirement of keeping the percentage of the exposed population who are highly annoyed with wind turbines to less than $10 \%$. In fact, reading the $L_{\mathrm{den}}$ to the nearest $0.1 \mathrm{~dB}$ from both the mean average European curve and the Japanese curve in the Fig. 16 of the WHO report [5] at which $10 \%$ of people are highly annoyed with wind turbines gives $43.7 \mathrm{~dB}$ $L_{\mathrm{den}}$ which is equal to $37.3 \mathrm{~dB} L_{\text {Aeq }}$. It appears that the WHO sound level limit was rounded to the nearest $5 \mathrm{~dB}$. The WHO analysis did not include the 2016 results of Michaud et al. [8-11]. If the committee's sound level limit [3] is determined to the nearest $0.1 \mathrm{~dB}$, rather than the nearest $1 \mathrm{~dB}$, the limit is $35.3 \mathrm{~dB} L_{\mathrm{A} 90(10 \mathrm{~min})}$, which is equal to $37.3 \mathrm{~dB}$ $L_{\text {Aeq, }}$, and is equal to the $\mathrm{WHO}$ value to the nearest $0.1 \mathrm{~dB}$. Note however that the uncertainty limits are large. The WHO report found six studies which it rated as low quality, and which did not reveal consistent results about effects of wind turbine noise on sleep disturbance. The WHO report found no studies on the effects of wind turbine noise on the prevalence of ischaemic heart disease, hypertension, permanent hearing impairment, and reading skills and oral comprehension in children.

The committee recommends that state and territory governments consider harmonising their wind turbine sound limits by adopting the limits proposed in their paper [3]. It would also like to see more uniformity in sound measurement and compliance requirements. Although the committee believes that wind turbine sound level should be the primary determinant of how close residences can be to wind turbines, 
there should also be a minimum setback distance. This minimum distance may be varied under particular circumstances, such as when the residences are exposed to the same high winds as the wind turbines themselves. This produces high background noise levels at the residences and allows the residences to be exposed to a higher level of wind turbine noise and hence to be effectively closer to the wind turbines than would normally be the case. With current wind turbine technology, this minimum distance should be in the range between the $1 \mathrm{~km}$ adopted by the Victorian Government and the $1.5 \mathrm{~km}$ recommended by the National Health and Medical Research Council and adopted by the Queensland Government. These minimum distances may need to be revised in the future due to technology changes.

\section{Possible Perceptual and Physiological Effects of Wind Turbine Infrasound and Low-Frequency Noise}

In a further publication, the committee [12] recognised and responded to the need to review the scientific literature relating to possible perceptual and physiological effects of infrasound and low-frequency sound (IS/LF). Previous reviews [13-21] have mostly relied on an epidemiological approach providing meta-analysis of the existing populationbased research. As outlined in Appendix, the sensitivity of this approach appears quite low. By contrast, the committee focussed on physiological mechanisms at the level of the individual to determine if there was evidence of an effect of IS/LF sound energy on the organism.

Studies of the generation and propagation of IS/LF sound by wind turbines demonstrate that the acoustical energy per unit frequency at the blade-passing frequency (BPF) and at its harmonic frequencies below $10-15 \mathrm{~Hz}$ is greater than at higher frequencies. Propagation models and field studies have indicated that sound at these IS/LF frequencies can propagate with less attenuation with distance than higher frequencies because of their lower sound absorption during passage through the air and on reflection from the ground [12, 22-28]. Added to this is uncertainty regarding the effectiveness of sound insulation of houses at infrasound and low frequencies [29]. Given these uncertainties, there was a paucity of data relating to the potential exposure of individuals in the vicinity of wind turbines, particularly within dwellings where they work and sleep.

Reviews of physiological transduction and neural excitation provided a strong prima facia case for the transduction of IS/LF [12, 30, 31] and stimulation of the human nervous system consistent with studies demonstrating perceptual sensitivity to high levels of IS/LF sounds and to neural (cortical) activation at more moderate sound levels [12, 32-34]. While these data do not by themselves, speak to the health effects or not of wind turbine noise (WTN), they do demonstrate that such sounds are encoded by the human nervous system.

The committee concluded, consistent with other studies by the NHMRC, that the quality of data relating to the potential health effects of WTN was not good. The review identifies a range of research questions that would be appropriate for further detailed study in order to address the many outstanding scientific questions. In brief, these included:

1. Characterization and modelling of the sound generated by modern windfarms focusing on the blade-passing frequency (BPF) and higher harmonics along with the effects of terrain and atmospheric conditions, etc.;

2. The development of a more complete understanding of the interactions between WTN and the built structures in which people live and sleep;

3. New methods need to be developed for measuring acute and chronic exposure (dosimetry);

4. Structural and aeronautic engineering research to minimize the sound pressure level at the BPF;

5. Effects of IS/LF on the cochlea and vestibular apparatus;

6. A better understanding of the neural connectivity of the inner ear and an understanding of the neural and behavioural consequences of their possible activation by IS/ LF;

7. Studies of individuals who report susceptibility to WTN for dysfunction or pathology that mediates susceptibility (e.g. superior semicircular canal dehiscence or lymphatic hydrops).

The committee believes that further scientific research is needed to discover why some people complain about being badly affected by wind turbine noise. It recommends that the NHMRC and ARC consider the research agenda outlined above for increased priority funding as one means to address this potentially important public health and policy, energy security and scientific issue.

\section{Effects on Sleep Health and Quality of Life}

Most of the wind turbine noise limits that were described in the committee's earlier manuscript [3] were set to avoid sleep disturbance using generic noise studies and the sound insulation provided by partially open windows. Thus, it makes sense to look at what evidence there is for a relationship between wind turbine noise levels and sleep disturbance.

The NHMRC [6] stated that there is inconsistent, poor quality direct evidence of an association between sleep disturbance and wind farm noise. They observed that sleep disturbance was not objectively measured in the studies and that a range of other factors could explain the associations that 
were observed. Michaud et al. [11] used both self-reported and objective measures of sleep quality. They concluded that there was no association between the exposure to outdoor wind turbine noise of up to $46 \mathrm{~dB}(\mathrm{~A})$ and sleep disturbance. Micic et al. [35] have pointed out the limitations of this study and the other studies discussed in this section. It the case of the Michaud et al. study, these limitations included the use of actigraphy for the objective measure of sleep and the use of calculated sound levels which ignored special audible characteristics.

van den Berg [36] stated that Janssen et al. [37] had analysed the sleep disturbance data from two Swedish and one Dutch study whose annoyance data were used in the committee's paper [3]. Janssen et al. only found a statistically significant relationship between sleep disturbance and wind turbine noise level when they excluded persons who received economic benefit from the wind turbines $[36,37]$. When all residents were included, there was no statistically significant relationship. However, there may be a small percentage of the population with individual sensitivities which would not be discovered by a study of this size. It should be noted that the sleep disturbance was not necessarily from wind turbine noise.

Bakker et al. [38] further analysed the data on residents from the Dutch study who received no economic benefit. They found no statistically significant relationship between sleep disturbance and wind turbine noise level. There was a statistically significant relationship between annoyance and sleep disturbance. In the quieter rural areas, there was also a statistically significant relationship between annoyance and wind turbine noise level.

Pedersen [39] re-analysed the data from the two Swedish and one Dutch study. Pedersen found that there was a statistically significant relationship between wind turbine noise levels and sleep disturbance for the first Swedish study [40] and the Dutch study [41]. The second Swedish study [42] highlights other factors, in addition to sound levels that influence perception of and annoyance with wind turbine noise including individual characteristics, such as noise sensitivity and attitude to the source, and the influence of dissimilar environments, including the influence of terrain. Hence it appears too simplistic to use analysis of sleep disturbance in terms of wind turbine noise levels alone to set limits for wind turbine noise, as other factors are also involved.

van den Berg [36] has concluded that audible noise from wind turbines may cause annoyance which aggravates sleep problems. Hence wind turbine noise limits which prevent annoyance may also prevent sleep disturbance. Thus, an alternative approach may be to set wind turbine noise limits using the percentage of people who are highly annoyed given the current state of knowledge.

The NHMRC [6] concluded that there is no consistent evidence that wind farms cause adverse health effects in humans.
This statement was re-enforced by the Health Canada study [10]. However, it should be noted that the NHMRC [6] also stated that the evidence is of poor quality. Because of the concern expressed by some people, they recommended further high-quality research into the possible health effects of wind farms. To be clear, in a situation where data quality is poor, it is not possible to draw a secure positive or negative conclusion with respect to the question of the association between wind turbine noise and health effects.

For instance, according to Feder et al. [43], there have been a few studies on the relationship between quality of life and wind turbine noise level and the findings are inconsistent. One group [44, 45] showed that quality of life improved with closer proximity to a wind farm, suggesting other factors apart from sound levels, influence this. On the other hand, Shepherd et al. [46] found that the quality of life decreased when the wind farm noise level increased. Onakpoya et al. [19] cites this and several other studies to support the relationship, but they noted some that did not and they were unable to conduct a meta-analysis because of inconsistency in the quality of life measures used across these studies. Given the absence of consistent data regarding the effects of wind turbine noise on quality of life data, it appears that quality of life measures alone cannot currently be recommended to set wind turbine noise limits.

Most of these studies used very small numbers of participants, which deprives the analyses of an appropriate level of statistical power to detect small influences in the larger population (see "Appendix"). These studies do not provide consistent evidence regarding the influence of wind turbine noise on sleep health and quality of life or distinguish these influences from others in helping determine reasonable wind turbine noise limits. This lack of consistency suggests that some effects may only be experienced by a small proportion of the population making their detection problematic where studies with low participant numbers are used to detect them.

The committee supports the conclusions of the National Health and Medical Research Council that there is currently no consistent evidence regarding the effects of wind farms on human health and their call for high quality research into the matter, particularly where close proximity (within $1500 \mathrm{~m}$ ) is involved [6]. The committee notes that the wind turbine industry is a very large and growing industry worldwide and such an investment could provide significant advantage to Australian industry.

\section{Low-Frequency Noise Limits}

Because of the concern that has been expressed about the possible effects of low-frequency noise from wind turbines, it is appropriate to review existing or proposed 
low-frequency noise limits from around the world. Table 1 shows reference curves which have been used or suggested to be used for the control of generic low-frequency noise. Table 1 is taken from Leventhall et al. [47] and the reference curve recommended to DEFRA in the UK by Moorhouse et al. [48] has been added to the table. The ISO 226 values are the threshold of human hearing sound levels taken from a version of ISO 226 [49] which is no longer current. Except for the Polish and Danish night values which are based on A-weighted values, the values are similar to the human threshold values at $50 \mathrm{~Hz}$ and below. This means that the creators of these limits considered that low-frequency noise close to the hearing threshold could be annoying. Zajamšek et al. [26] have shown that indoor third octave band sound pressure levels of wind turbine noise below $50 \mathrm{~Hz}$ are significantly below the human hearing threshold. This leads some researchers to believe that wind turbine noise below $50 \mathrm{~Hz}$ is not a problem [50-53]. However, as noted in the committee's previously published analysis [12], not all researchers agree that this is the case $[25,30,31,54]$.

It should be noted that these criterion curves are applied in different ways. Table 2 shows the Danish indoor noise criteria [55]. $L_{\mathrm{A}, \mathrm{LF}}$ is the A-weight noise in the 10 to $160 \mathrm{~Hz}$ third octave bands. The Danish evening and night time third octave band sound levels must be sufficiently below the $20 \mathrm{~dB}(\mathrm{~A})$ contour values shown in Table 1 , so that the combination of these third octave band values does not exceed $20 \mathrm{~dB}(\mathrm{~A})$. The value of the $20 \mathrm{~dB}(\mathrm{~A})$ contour for each third octave band is the sound pressure level in that third octave band which on its own has a sound level of $20 \mathrm{~dB}(\mathrm{~A})$. The infrasound criterion is not greater than 85 or $90 \mathrm{~dB}(\mathrm{G})$ [55], which wind turbine noise is well known to easily satisfy. A $5 \mathrm{~dB}$ penalty is added to the measured values for impulsive noise such as single blows from a press or drop forge hammer.

The Polish requirement is that noise is considered to be annoying if any third octave band level is greater than the $10 \mathrm{~dB}(\mathrm{~A})$ contour shown in Table 1 and greater than $10 \mathrm{~dB}$ for tonal noise or $6 \mathrm{~dB}$ for broadband noise above the third octave band background noise level. This is the reason why the Polish curve is $10 \mathrm{~dB}$ lower than the Danish curve. The value of the $10 \mathrm{~dB}(\mathrm{~A})$ contour for each third octave band is the sound pressure level in that third octave band which on its own has a sound level of $10 \mathrm{~dB}(\mathrm{~A})$.

Table 1 Low-frequency noise criterion curves

\begin{tabular}{|c|c|c|c|c|c|c|c|}
\hline Frequency $\mathrm{Hz}$ & $\begin{array}{l}\text { Poland } \\
10 \mathrm{~dB}(\mathrm{~A}) \text { contour }\end{array}$ & $\begin{array}{l}\text { Germany } \\
\text { DIN } 45680 \mathrm{~dB}\end{array}$ & $\begin{array}{l}\text { Netherlands } \\
\text { NSG dB }\end{array}$ & $\begin{array}{l}\text { Denmark Night } \\
20 \mathrm{~dB}(\mathrm{~A}) \text { contour }\end{array}$ & $\begin{array}{l}\text { Sweden } \\
\mathrm{dB}\end{array}$ & $\begin{array}{l}\text { UK } \\
\text { DEFRA dB }\end{array}$ & $\begin{array}{l}\text { ISO } 226 \\
\mathrm{~dB}\end{array}$ \\
\hline 8 & & 103 & & & & & \\
\hline 10 & 80.4 & 95 & & 90.4 & & 92 & \\
\hline 12.5 & 83.4 & 87 & & 93.4 & & 87 & \\
\hline 16 & 66.7 & 79 & & 76.7 & & 87 & \\
\hline 20 & 60.5 & 71 & 74 & 70.5 & & 74 & 74.3 \\
\hline 25 & 54.7 & 63 & 64 & 64.7 & & 64 & 65 \\
\hline 31.5 & 49.3 & 55.5 & 55 & 59.4 & 56 & 56 & 56.3 \\
\hline 40 & 44.6 & 48 & 46 & 54.6 & 49 & 49 & 48.4 \\
\hline 50 & 40.2 & 40.5 & 39 & 50.2 & 43 & 43 & 41.7 \\
\hline 63 & 36.2 & 33.5 & 33 & 46.2 & 41.5 & 42 & 35.5 \\
\hline 80 & 32.5 & 28 & 27 & 42.5 & 40 & 40 & 29.8 \\
\hline 100 & 29.1 & 23.5 & 22 & 39.1 & 38 & 38 & 25.1 \\
\hline 125 & 26.1 & & & 36.1 & 36 & 36 & 20.7 \\
\hline 160 & 23.4 & & & 33.4 & 34 & 34 & 16.8 \\
\hline 200 & 20.9 & & & & 32 & & 13.8 \\
\hline 250 & 18.6 & & & & & & 11.2 \\
\hline
\end{tabular}

Table 2 Danish generic noise criteria

\begin{tabular}{llll}
\hline & $\begin{array}{l}\text { Infrasound } L_{\mathrm{G}} \\
(\mathrm{dB})\end{array}$ & $\begin{array}{l}\text { Low-frequency } \\
\text { noise }(\mathrm{dB})\end{array}$ & Normal noise limit $L_{\mathrm{A}}(\mathrm{dB})$ \\
\hline Dwelling, evening and night & 85 & 20 & $30 \mathrm{~dB} / 25 \mathrm{~dB}$ \\
Dwelling, day & 85 & 25 & $30 \mathrm{~dB}$-day and evening \\
Classroom, office etc. & 85 & 30 & $40 \mathrm{~dB}$ \\
Other rooms in enterprises & 90 & 35 & $50 \mathrm{~dB}$ \\
\hline
\end{tabular}


According to Leventhall [47], in the application of the Swedish method, the noise may be considered a nuisance if its level exceeds the criterion curve in any third octave band. In the Dutch method, the LF sound is considered audible and potentially annoying if the equivalent third octave sound pressure level is above the reference curve at one or more frequencies [56]. The DEFRA method [48] requires any third octave band $L_{\mathrm{eq}}$ which exceeds the criterion curve to be investigated. The criterion curve is relaxed by $5 \mathrm{~dB}$ if the noise occurs only during the day or if the noise is not fluctuating.

Leventhall [47] has described the German DIN 45680 method. The difference $(\mathrm{dB}(\mathrm{C})-\mathrm{dB}(\mathrm{A}))>20 \mathrm{~dB}$ is used as an initial indication of the presence of low-frequency noise. The noise is then measured in third octaves over specified time periods and compared with the threshold curve in Table 1. The main frequency range is from $10 \mathrm{~Hz}$ to $80 \mathrm{~Hz}$. Frequencies of $8 \mathrm{~Hz}$ and $100 \mathrm{~Hz}$ are used only if the noise has many components within the range $10 \mathrm{~Hz}$ to $80 \mathrm{~Hz}$. DIN 45680 assumes that the great majority of lowfrequency noise problems from industrial sources are tonal and that thus the $8 \mathrm{~Hz}$ and $100 \mathrm{~Hz}$ third octave bands will only rarely be used. If the level in a third octave band is $5 \mathrm{~dB}$ or more above the level in the two neighbouring bands, the noise is described as tonal. For tonal noises, the level of the tone above the hearing threshold is found. All the limits are reduced by $5 \mathrm{~dB}$ during night-time.

Other possible low-frequency noise requirements are upper outdoor limits of $L_{\mathrm{Ceq}}$ equals $65 \mathrm{~dB}(\mathrm{C})$ during the day and $60 \mathrm{~dB}(\mathrm{C})$ during the night $[57,58]$. As stated above, the difference $(\mathrm{dB}(\mathrm{C})-\mathrm{dB}(\mathrm{A}))>20 \mathrm{~dB}$ is also sometimes used as an initial indication of the presence of low-frequency noise. Broner and Leventhall [59] have proposed the use of Low-Frequency Noise Rating (LFNR) curves. Inukai et al. [60] developed a new weighting curve for low-frequency noise. Vercammen $[61,62]$ developed low-frequency noise limits which appear to be the forerunner of the Danish limits.

In urban environments, Evans et al. [63] found that A-weighted low-frequency noise levels at all locations regularly exceed the night time residential criteria of $20 \mathrm{~dB}(\mathrm{~A})$ used in Denmark (between 16 and $86 \%$ of the time). These excluded periods affected by people's daily activities. The DEFRA night-time low frequency noise criteria were also regularly exceeded at the urban locations.

In rural environments Evans et al. [63] found a lower level of low frequency noise in the environment at the four rural locations relative to the seven urban locations. The measured night-time $L_{\mathrm{A}, \mathrm{LF}}$ levels at four rural locations exceeded the $20 \mathrm{~dB}(\mathrm{~A})$ Danish criterion for only $10 \%$ of the time or less. This $20 \mathrm{~dB}(\mathrm{~A})$ criterion was not exceeded at one of the rural locations. The levels of low frequency noise were correlated to wind speed at the measurement site. At some locations, they were also affected by the presence of people within a space. The levels of low frequency noise at the two wind farm locations, which were approximately 1.5 kilometres away from the nearest wind turbine, were low in comparison with the urban areas and were not noticeably higher than at the other two rural locations. It should be noted that although this study did give the time of day and the wind speed when the measurements were made, it did not give the power output or other meteorological data. The low frequency levels at one location remained below the Danish and DEFRA criteria at all times. The outdoor levels remained below $60 \mathrm{~dB}(\mathrm{C})$ during the night-time periods. The Danish $20 \mathrm{~dB}(\mathrm{~A})$ nighttime criterion was exceeded for $10 \%$ of the measurement time at another location. This was believed to be due to the construction of the house rather than the contribution of noise from Clements Gap Wind Farm. There were very occasional exceedances of the night-time DEFRA criteria at this site, but the percentage of exceedances was no greater than at two other locations with no wind turbines within 10 kilometres. Hansen et al. [64] measured wind farm noise in the $50 \mathrm{~Hz}$ third octave which was well above the DEFRA limit.

Organised shutdowns showed that the contribution of the Bluff Wind Farm to low frequency noise levels at one location was negligible. There may have been a relatively small contribution of low frequency noise levels at this location from the Clements Gap Wind Farm at frequencies of $100 \mathrm{~Hz}$ and above. However, Hansen et al. [65] did find a substantial reduction in the low frequency noise levels during a shutdown of the Waterloo Wind Farm relative to levels during operation.

It is worth noting that the frequency ranges considered by all the standards discussed above do not extend to the blade-passing frequencies and the early harmonics (approximately $0.5-8.0 \mathrm{~Hz}$ ) which represent the largest components of IS and LF energy emitted by wind turbines. As discussed under 'Possible perceptual and physiological effects of wind turbine noise' above, there is a prima facia case for the somatic and/or neural transduction of these frequencies, and Zajamšek et al. [26] found that wind turbine noise did increase the infrasonic and low frequency noise during quiet night time periods.

The committee is unable to recommend low frequency sound or infrasound limits for wind farms in the absence of definite evidence of the health effects of low frequency sound or infrasound from wind turbines. There would also need to be a reliable method of measuring low frequency noise and infrasound before a limit could be imposed. One possible method is described in ANSI/ASA S12.9-2016/ Part 7 [66]. The committee recommends that research on the possible impact of low frequency sound and infrasound on humans from industrial sources including wind turbines is continued. 


\section{Alternative Causes of Annoyance}

It has been demonstrated experimentally that people suffer more health problems if they are led to believe that wind turbines are harmful (nocebo effect) [67-69]. This is an example of the well-known psychological bias referred to as the 'demand characteristic' in perceptual and social psychological research.

Michaud et al. [8] examined the statistically significant variables related to annoyance with wind turbines using a multiple logistic regression model. The importance of each variable was ranked using the Nagelkerke pseudo $R^{2}$. The closer the Nagelkerke pseudo $R^{2}$ is to $100 \%$, the better the multiple logistic regression model equation predicts the observed probability of occurrence. Wind turbine noise level had an $R^{2}$ equal to $9 \%$. This increased to $11 \%$ when the location in Canada was added to form the base model. Addition of further variables including those related to other wind turbine annoyance, personal benefit, noise sensitivity, physical safety concerns, property ownership and the location within Canada of the operation lifted the $R^{2}$ value to $58 \%$ (meaning that $58 \%$ of the variance in the relationship of annoyance to wind turbines could be explained by them). This suggests that wind turbine noise alone is not a powerful predictor of annoyance, and that many other factors contribute to the problem.

In further analysis Michaud et al. [8] noted that while they failed to find a relationship between wind turbine noise levels and sleep disturbance, the strongest association with annoyance was identifying wind turbines as the source of noise that led to window closing because it was disturbing sleep. They suggested that closing the window may be an expression of the annoyance towards WTN and/ or a coping strategy that protects against sleep disturbance. Given that closing the window reduces the indoor WTN level and hence improves sleep, this action may conceivably explain the absent association between WTN levels and sleep disturbance.

Michaud et al. [8] also noted that concern for physical safety due to the presence of wind turbines was a significant predictor of annoyance in both the unrestricted and restricted models suggesting that actions (such as education and community consultation) which address this concern during the planning stages of a wind project may reduce community annoyance toward wind turbine noise. Noise sensitivity influences the response to community noise. Thus, it is not surprising that noise sensitivity was associated with wind turbine noise annoyance [8]. Crichton et al. [67] have confirmed this observation by showing that giving people positive expectations about exposure to wind turbine noise can statistically significantly reduce their health symptoms. This is another example of the 'demand characteristic'.
Michaud et al. [8] further observed that personal benefit was not retained in their unrestricted modelling of the relationship between wind turbine noise and annoyance, although this was probably due to the small number of participants in this category. Personal benefit was found to be statistically significant in their restricted model, although the associated increase in $R^{2}$ with addition of this variable was only $3 \%$. Together with Pedersen et al. [41], these findings support the distribution of direct or indirect personal benefits to participants living in close proximity to wind power projects.

The finding that wind turbine noise level alone is not a particularly strong predictor of annoyance with wind turbines suggests that other actions should be undertaken in conjunction with the setting of wind turbine noise limits in order to reduce annoyance. Furthermore, it needs to be recognized that even small effects can be important as they may reflect the influence of a limited number of individuals with particular sensitivities that need to be accounted for [47].

The committee recommends that wind farm developers educate, consult with and provide some resources to the local community in order to identify and minimise the diverse potential sources of annoyance with wind farms.

\section{Annoyance Attributed to Low Frequency Noise}

In various settings around the world, a small percentage of people report being annoyed by what they perceive as persistent low frequency noise, usually from an unknown or undiscovered source as obvious sources have been eliminated. This phenomenon is often referred to as 'The Hum'. It is helpful to examine reports of 'The Hum' because its reported symptoms are similar to some of the symptoms reported by some people living near wind turbines [47, 70-73]. The Hum is perceived as a low frequency noise which is often described as a throbbing noise. It is probably, but not necessarily, caused by low frequency noise from industrial or other anthropogenic noise sources. There have been several attempts to find the cause of the Hum recorded in the literature [70, 72, 73]. However, Leventhall (2004) notes that 'No widespread Hum has been unequivocally traced to specific sources, although suspicion has pointed at industrial complexes, especially fans'. Even when low frequency sound sources have been found and quietened, this has not usually solved the problem completely [71].

The effects of the Hum are reported as pressure or pain in the ear or head, body vibration or pain, loss of concentration, nausea and sleep disturbance. [47]. These general effects are reported internationally.

Unsympathetic handling of the complaint builds up stress and exacerbates the problems. Hum sufferers tend to be 
middle aged and elderly. They often have a low tolerance level and are prone to negative reactions [47]. Personal tensions are reduced if the complaints are taken seriously by the authorities because this eases the additional stresses which occur when they are not believed [47].

Leventhall et al. [47] summarised Vasudevan and Gordon's [73] experience from investigating the Hum as follows:.

- The problems arose in quiet rural or suburban environments.

- The noise was often close to inaudibility and heard by a minority of people.

- The noise was typically audible indoors and not outdoors.

- The noise was more audible at night than during the day.

- The noise had a throbbing and rumbly characteristic.

- The main complaints came from the 55-70 years age group.

- The complainants had normal hearing.

- Medical examination excluded tinnitus.

These are now recognised as classic 'hum' descriptors.

It is often the case that only one person in a family is sensitive to the Hum [47]. If the Hum is caused by sound, the fact that it is only 'heard' by a small minority of people suggests that these people have more sensitive hearing than the rest of the population. It has been suggested that the percentage of people in the effected age group who might be able to hear the Hum is $10 \%$ [56], 2.5\% [71] or 0.5\% [47]. Leventhall et al. [47] assumed that the people most likely to suffer from the Hum were in the 50-59 age group who comprise about $10 \%$ of the population. This meant that the percentage of the total population likely to suffer from the Hum is estimated to be $1 \%, 0.25 \%$ or $0.05 \%$. While these estimates are obviously very imprecise, they suggest that if 'The Hum' is responsible for any wind turbine health effects, population-wide epidemiology studies may not be sufficiently sensitive to detect them. Rather, approaches that identify outliers, clusters or more sophisticated forms of frequentist statistics will need to be employed, as they are more appropriate to identifying and describing low prevalence events and low disease rates. Relevant to this, there are two current NHMRC funded projects examining wind turbine noise effects on sleep which intend to increase the capacity to identify possible underlying dysfunctions or sensitivities by selecting noise-sensitive people.

\section{Amplitude Modulation}

Psychoacoustic studies have generally shown that sound with varying temporal or frequency characteristics is more noticeable and more annoying than constant 'steady-state' noise.
Some wind turbine noise policies in Australia and overseas include penalties for sound from wind farms that has 'special audible characteristics' (known as SACs) that are likely to make it significantly more noticeable and annoying to sensitive receivers. One of the key 'special audible characteristics' of wind farm sound is the amplitude modulation (AM) of the sound over time as the turbine blades are turning, which results in a rise and fall in wind farm loudness. This is usually characterised as a 'whoosh-whoosh-whoosh' sound modulated at the blade-passing frequency (usually around $1-2 \mathrm{~Hz}$ ). This sound is usually evident, to some extent, in all wind turbine sound due to the nature of the noise generation mechanism at the turbine blade. However, the extent (or level) of modulation, known as the modulation depth, can vary significantly depending on the environmental conditions, and some objective measure of the extent of amplitude modulation, and its acceptability, is required. Some simple objective measures for AM were documented in the early wind farm sound policies and standards, but there is generally a concern that these were not rigorously developed, and their relationship to the extent of annoyance has never been adequately demonstrated.

Lee et al. [74] have studied the annoyance caused by amplitude modulated wind turbine noise using 30 people. They showed that the A-weighted equivalent sound level and the modulation depth both had a statistically significant effect on the annoyance. However, the annoyance differences between different modulation depths were only statistically significant when the difference in modulation depths was large. von Hünerbein et al. [75] showed that after removing the effect of the A-weighted equivalent sound level, the annoyance increased monotonically with the modulation depth, but this increase was not statistically significant due to the small sample size of 20 people. Bockstael et al. [76] found a statistically significant link between annoyance and their measure of amplitude modulation. Ioannidou et al. [77] found a statistically significant relationship between annoyance and the amplitude modulation depth of wind turbine noise. Yokoyama et al. [78] showed that amplitude modulation of wind turbine noise became noticeable when the modulation depth exceeded $2 \mathrm{~dB}$.

The Institute of Acoustics (IoA) in the UK [79] has conducted an extensive study into the best way to objectively measure amplitude modulation of wind turbine noise. The IoA looked at time-series methods, frequency-domain methods, and hybrid methods. They have recently recommended the use of a relatively complex hybrid method. This is quite a complicated procedure which could possibly result in implementation differences between users. Therefore, the IoA has issued open-source Python software which carries out this procedure in an accepted and consistent manner.

Large [80] has compared the three initial amplitude modulation rating methods proposed by the IoA with the 
annoyance ratings of 6 samples of wind turbine amplitude modulation (AM) made by 336 people. She noted that the AM rating methods 'generally followed the shape of the annoyance ratings' but that the range of the AM ratings was much greater than the range of the annoyance ratings. Hence some caution is needed, but the current IoA amplitude modulation rating method is the best candidate for trial in Australia. It should be noted that none of the AM rating systems so far proposed include the possible effect of basilar membrane biasing by the blade-passing tone and its harmonics [12]. Hansen et al. [81] have shown that the IoA method may need to be modified in some circumstances, particularly when the amplitude modulation is of a tone below $50 \mathrm{~Hz}$.

The IoA have deliberately avoided specifying how their rating scheme should be used for rating the noise output of wind turbines. Perkins et al. [82-84] have proposed that there be no penalty for an amplitude modulation rating which is less than $3 \mathrm{~dB}$. For amplitude modulation ratings between $3-10 \mathrm{~dB}$, the penalty increases linearly from a $3 \mathrm{~dB}$ penalty at $3 \mathrm{~dB}$ AM depth, to $5 \mathrm{~dB}$ penalty at $10 \mathrm{~dB}$ AM depth. Above $10 \mathrm{~dB}$ AM, the penalty is fixed at $5 \mathrm{~dB}$. This penalty is added to the measured $L_{\mathrm{A} 90}$ values and is in addition to any tonal penalty. Perkins et al. [82] have observed that 'AM generates the greatest adverse impact during nighttime or early morning periods'. Because ETSU-R-97 [4] recommends a higher night time wind turbine noise level limit for England, Perkins et al. [82] recommend that the same limit for AM for England be applied all the times by adding the difference between the night time limit and the day time limit to the AM penalty. This implies that they believe that the ETSU-R-97 higher night-time wind turbine noise level limit does not make sense. There has recently been further debate about appropriate penalties for amplitude modulation [85].

The draft New South Wales planning guidelines [86] impose a penalty of $5 \mathrm{~dB}$ when the amplitude modulation depth is greater than $4 \mathrm{~dB}$. However, their maximum penalty is $5 \mathrm{~dB}$, so that where more than one special audible characteristic penalty potentially applies, only one of the penalties is added to the measured sound level.

The committee recommends that the United Kingdom Institute of Acoustics objective measurement method of measuring amplitude modulation and the WSP Parsons Brinckerhoff method of penalising amplitude modulation be trialled in Australia.

\section{Tonality}

Tonality is the difference between the tone level and the level of the masking noise in the critical band around the tone. Tonal elements are particularly salient, and potentially annoying. It is common to penalise tonal sounds when rating sound signals because they are usually found to be more subjectively disturbing than broadband sound at the same level. Usually, the approach is to add a positive penalty to the measured sound level, rather than reduce the limit for sound containing tones. For wind farm noise, it is necessary to determine both the best scheme or approach to measure tonality and where it should be measured.

In terms of the measurement location, it is possible to measure tonality near the turbines themselves, at the receiver, or somewhere in between. Clearly, it is particularly relevant at the receiver, and a measurement near to the turbine is less critical because a sound source that is tonal near to the source, will not necessarily result in tonal noise at the more distant receiver, where the sound is combined with the ambient sound local to the receiver, which can significantly mask the tonal elements. Nevertheless, the presence of tonality in the source signal is easier to measure near the source because of the better signal to noise ratio. One approach that has been suggested is to make a measurement near the turbines as an 'exclusion test', since, if the sound near the turbines is not tonal, then it is unlikely to be tonal at the receiver. More intrusive tests at the receiver would therefore not be warranted. However, if the wind turbine sound did prove to be tonal near the turbines, this could be used to suggest what tonal frequency should be searched for near the receiver (and, if tonal frequencies are measured at the receiver, what tonal frequencies could be excluded from being generated by the wind turbines).

If measurements of tonality are made only at the receiver, and not in conjunction with a measurement made near the turbine, then it can be difficult to discriminate tonality from the wind turbines from ambient noise such as Aeolian noise emissions from wire fences, etc. One approach is to limit measurements to the downwind condition. Another possibility is to make measurements only at night when the ambient noise is likely to be quieter. A problem with making downwind measurements of tonality, is that the tonality can sometimes only be audible to the side and upwind of the turbine [87].

In terms of the best approach to measuring and assessing tonality, it is usually helpful to conduct a less complicated subjective screening test prior to making objective measurements. This is usually undertaken by an acoustic engineer or other qualified person simply listening for the potential of tonality in wind farm sound or site recordings. A potential problem with this approach is that tonality sometimes only occurs for a narrow range of wind speeds and only for certain directions from the wind turbine and at certain times [87]. Thus, having the expert listener make a judgement at the right time may be difficult. Having the affected person make a recording when they hear tonality may overcome this problem. 
If the potential for tonality is detected, then further objective measurements of tonality can be made in accordance with Annex C of ISO 1996-2:2007 [88]. This method is based on the Joint Nordic Method-Version 2 [89]. It is a tonal audibility method, based on narrowband analysis. It requires considerable signal processing and results in the calculation of tonal audibility and an adjustment penalty between 0 and $6 \mathrm{~dB}$.

However, because this reference method is complicated, ISO 1996-2:2007 [88] also contains a simplified method in Annex D. If the time-averaged sound pressure level in a onethird octave band exceeds the time-averaged sound pressure levels in both the adjacent two one-third octave bands by a level difference, a penalty, which is usually $5 \mathrm{~dB}$, is applied. The suggested level differences are:

$15 \mathrm{~dB}$ in the low-frequency one-third-octave bands (25$125 \mathrm{~Hz}$ ),

$8 \mathrm{~dB}$ in middle-frequency bands $(160-400 \mathrm{~Hz})$,

$5 \mathrm{~dB}$ in high-frequency bands $(500-10,000 \mathrm{~Hz})$.

This simplified method can fail to identify low frequency audible tones because of the tone's side bands if the tone is substantially amplitude modulated [90].

(Note: These methods have been updated in Annex J of ISO/PAS 20065:2016 [91] and Annex K in ISO1996-2:2017 [92]. Also, there is an alternative tonality method in ETSUR-97 [4].)

If a sound is identified as tonal, then it becomes necessary to assess how much 'tonality' is unacceptable and how the penalty should be applied to the $10-\min L_{\mathrm{A} 90}$ wind farm sound level measurements. NZS 6806:2010 [93] implies that if tonality is detected, then the penalty should be applied to each $10 \mathrm{~min} L_{\mathrm{A} 90}$ measurement, and that each penalised measurement should then be included in the regression analysis. If these modified measurements are sufficient to affect this regression, then the tonality effect is considered to be 'influential'.

The NZ Standard does not provide guidance regarding how much of the 10-min measurement can exhibit tonality in order to necessitate applying the penalty. For example, should the entire 10-min measurement exhibit tonality in order to apply the penalty, or should the penalty apply if only part of the measurement is tonal? In practice, there is considerable variability, and it would be unusual for an entire 10-min noise measurement period to exhibit objectively measured tonality. For the Te Rere Hau review [94] in New Zealand, it was accepted that if $2 \mathrm{~min}$ of the period exhibited measurable tonality, then the tonal penalty should apply to the whole period's sample. If more than one tone in one period produces a penalty, it was decided that only one penalty (the greatest of them) should be applied to the period.
At the Te Rere Hau review, it was argued that if $10 \%$ of measurements within a $1 \mathrm{~m} / \mathrm{s}$ wide wind speed bin were tonal, then the penalty should be applied to the windspeed bin. This approach requires bin analysis [95, 96], rather than polynomial regression. This approach was suggested because it would not overly penalise very infrequent occurrence of Special Acoustic Characteristics (SACs) but would apply an appropriate penalty to 'encourage mitigation' where SACs occur with reasonable regularity. A similar $10 \%$ threshold approach to applying the SACs penalty has been adopted in New South Wales and Queensland in Australia, and in the United Kingdom. However, this approach needs some refinement because it could result in a discontinuity in the compliance assessment (that is, a hard switch from compliant to non-compliant) near the $10 \%$ limit.

Nevertheless, there is concern that if only a small percentage of the measured 10-min sound levels are penalized for tonality, the effect of these penalized sound levels on the regression curve between the sound levels and the wind speeds, which is required by the NZ Standard NZS6808 to determine the sound level which is regulated, may not be significant. However, NZS6808-2010 [93] allows the sound levels measured over each $10 \mathrm{~min}$ period to be separated into a group of sound level measurements with acceptable tonality and a group of sound level measurements with unacceptable tonality. These two different groups of sound level measurements can be analysed separately. This allows the penalised periods to affect the regression between the measured sound levels and the wind speed when there is unacceptable tonality.

Several recent studies illustrate the complexities of investigation of the potential for tonality to influence perception of wind turbine noise and the annoyance related to it. Søndergaard and Pedersen [97] noted the technical difficulties in reconciling objective analysis of sound characteristics with subjective listening tests, pointing out for measurements conducted over lengthy periods, short periods of high tonality may not be detected. Yokoyama et al. [98] examined methods to assess the effect of tonal components on subjective perception of noise, both physically (perception) and psycho-acoustically (annoyance), demonstrating an influence of tonality on both aspects, but with considerable variability in the response between individuals. Oliva et al. [99] argue against using fixed penalty values for tonal sound, suggesting, based on their assessment, that these penalties should vary with tonal frequency, tonal audibility and overall level.

Further work is required. The committee recommends that detailed attention now be given to the potential for tonality to influence perception of wind turbine noise and annoyance related to it. This should include financial support for studies of the phenomenon and its behavioural implications. 


\section{Wind Farm Sound Measurement and Analysis}

The consideration of automated, unattended long-term measurement of wind farm sound is specifically raised in the Terms of Reference for the Committee and was suggested at the original Australian Senate hearing into wind turbine noise. Sound measurement, and particularly automated unattended noise monitoring seems to be seen as a common solution to wind farm problems and the management of wind farm noise. However, there are many practical issues with these types of sound measurement systems particularly related to the use of precision microphones in inhospitable measurement environments, ongoing calibration, and the use of signal processing to automatically positively identify particular sound sources contributing to the measured level at the sound level meter.

Nevertheless, within the industry, there has been a move towards conducting greater frequency analysis of wind turbine sound in addition to A-weighted sound level measurements, and to adopt real time telemetry and real time audio recordings. It is apparent that in future, as these technologies mature, it should be possible to use real-time wind turbine sound measurements to actively control and manage wind farms in order to satisfy sound level limits. In particular, all the relevant operating data of wind turbines are now routinely recorded using the Supervisory Control And Data Acquisition (SCADA) system in order to optimise wind farm performance and manage and undertake preventative maintenance. (SCADA is a system of software and hardware which allows the control and monitoring of industrial processes at local or remote locations and the processing of data in real time. SCADA is widely used in the wind turbine industry.) It is therefore an extension of these existing systems to record sound measurement and analysis data with the wind farm's SCADA system and potentially to use this data to control the wind turbines. It would be helpful if the wind farm industry were more willing to share this SCADA data with researchers and other stakeholders. It is reported that sharing of such data rarely occurs in Australia. While some of this data is commercially sensitive, it should be possible to draft suitable confidentiality agreements to allow this sharing to occur.

It is also important to note that there remain some potential legal issues in relation to the ongoing recording of sound related to people's privacy where sounds generated by people may be recorded. Such recordings could potentially breach various Australian States' Listening Devices Acts when using long term audio recordings, and further legal advice is required. One response may be to undertake the analysis of the sound at the measurement device itself, and only store or transmit the output of the analysis rather than raw audio signals.

The primary issue with any unattended sound monitoring and automated assessment is the potential for 'false-positive' sound level exceedances from unrelated local noise sources, rather than the subject sound source (wind turbines in this case). One approach to limiting 'false positive' noise level exceedance from automated unattended sound monitoring systems is to use directional microphone systems that limit the noise received from areas other than in the direction of the wind farm. The Australian developed 'Barn Owl' directional microphone system has been used successfully for this purpose around open cut mines. A similar cross-correlated microphone array has also occasionally been used for specific wind farm noise measurements in the USA. Unfortunately, such systems typically use additional microphones and complex signal processing and further complicate any automated unattended noise measurement system.

There are real practical issues with putting microphones outside in the field: they are calibrated, sensitive devices. There are ways to reduce these practical issues, but they are expensive. Some of these issues are discussed in detail in the committee's paper [12] in the context of the measurement of IS/LF energy from wind turbines. This is an area identified as a potential target for the investment of research funding.

Since wind farms are necessarily located in windy areas, there is a need to adequately protect microphones from wind noise while not affecting their ability to accurately measure the wind farm noise. This typically requires the use of special microphone wind shields incorporating a complex arrangement of inner and outer microphone wind screens. Protection against wind noise is easier if infrasound does not need to be measured and measurements only need to be made in the audible frequency range.

There are also practical and legal issues relating to the placement of any microphone measurement system. For example, it is sometimes necessary to rent space in which to place the microphone. This typically requires a large volume of legal work to write agreements which ensure appropriate access to data while restricting distribution of sensitive or commercial-in-confidence data. For instance, if a monitoring system is placed on stakeholder land, then the stakeholder may demand access to data which the wind farm operator is unwilling to disclose.

The committee recommends that wind farm operators be encouraged to continuously monitor wind turbine sound at some sensitive locations and be encouraged to incorporate these sound measurements as part of their SCADA systems. This sound data should be monitored by signal processing systems to detect unusual sounds such as tonality and excessive amplitude modulation. The Australian Government should consider investing in the development of such technology so that the resulting Australian IP could be 
incorporated internationally as a 'best in class' mechanism of monitoring.

\section{Management Strategies}

It is essential to ensure that wind turbine audible noise limits are implemented and observed. These are needed to ensure that: (a) the noise source is engineered and maintained to acceptable standards that limit noise generation and exclude abnormal noises; and (b) that suitable setbacks are provided to allow attenuation of sound emanating from the source to acceptable, near imperceptible levels beyond this setback distance. For the small percentage of people affected by wind turbine noise [100], despite such provisions, other strategies must also be considered. While one solution would be to assist these people to move away from wind turbine locations, this may not always be possible.

Leventhall et al. [101, 102] have used psychotherapy techniques such as cognitive behaviour therapy to help sufferers of low frequency noise cope with the noise. This work was supported by the United Kingdom Department for Environment, Food and Rural Affairs (DEFRA). These psychotherapy techniques may be of assistance to people suffering from annoyance from wind turbine noise. Unfortunately, these techniques appear to work best when the source of the noise is unknown, which is often the case with low frequency noise problems like "The Hum" as indicated in Sect. 6. With wind turbine noise, the source of the noise is well known. However, given that reported problems with wind turbine noise can in some cases be accounted for by annoyance and other psychological effects, then psychotherapy techniques may be appropriate form of management, although they are unlikely to be effective for all sufferers. Masking low pitched sound with low frequency brown and black noise is another therapeutic technique, which van den Berg and de Boer [103] found to be helpful for about half the people they studied who are annoyed by it.

The fact that some complaints about wind turbines occur before wind farms start operating means that sensitive treatment of residents during the planning and construction phases is essential. Distribution of financial benefits to effected residents will also help once the wind farm starts operating. Rapid response to any problems reported by residents is necessary.

\section{Conclusions}

This paper provides a review of important aspects of the real and potential impacts of wind turbines on human wellbeing. It considers wind turbine noise and its relationship to annoyance, sleep disturbance, quality of life and health.
It examines the ways that these effects can be assessed and mitigated. In so doing it provides an objective basis for harmonisation across Australia of provisions for siting and monitoring of wind turbines, which currently vary from state to state, contributing to contention and potential inequities between Australians, depending on their place of residence.

This paper shows that if rounding is removed, the outdoor wind turbine sound limits recommended by a recent World Health Organization report are the same as those recommended for use in Australia by this paper. These limits are derived by determining the wind turbine level at which $10 \%$ of people are highly annoyed with wind turbines. Annoyance is used to set these wind turbine noise limits because the level of annoyance with wind turbines is the only effect which consistently correlated with wind turbine noise sound level. It should be noted that this annoyance may not only be due to wind turbine noise. Wind turbine noise level may only be a proxy for distance from the wind turbines. On the other hand, this paper also surveys possible perceptual and physiological effects of wind turbine noise. The paper also looks at wind farm sound measurement and analysis including tonality and amplitude modulation, annoyance attributed to low frequency noise, low frequency noise limits and management strategies to reduce annoyance with wind turbines.

In summary, the committee suggests that 'annoyance' is the primary measure with which to set wind turbine noise limits and that the appropriate limit is one that ensures no more than $10 \%$ of the population would be highly annoyed when exposed to it. This threshold appears to be between 34-40 dB $L_{\text {Aeq (10 min) }}$ outside the residence, with a mean value of $37 \mathrm{~dB} L_{\text {Aeq (10 min) }}[3]$ and the committee urges harmonisation of state-by state guidelines around this standard. The perceptual and physiological effects, both known and suspected, of wind turbine noise justify such an effort.

Open Access This article is licensed under a Creative Commons Attribution 4.0 International License, which permits use, sharing, adaptation, distribution and reproduction in any medium or format, as long as you give appropriate credit to the original author(s) and the source, provide a link to the Creative Commons licence, and indicate if changes were made. The images or other third party material in this article are included in the article's Creative Commons licence, unless indicated otherwise in a credit line to the material. If material is not included in the article's Creative Commons licence and your intended use is not permitted by statutory regulation or exceeds the permitted use, you will need to obtain permission directly from the copyright holder. To view a copy of this licence, visit http://creativecommons.org/licenses/by/4.0/.

\section{Appendix: The Statistical Power of Wind Turbine Noise Studies}

Annoyance with wind turbines is the only of effect of wind turbines on their neighbouring populations which has been consistently discovered. This appendix investigates why 
other effects such as diseases caused by wind turbines have not been consistently found. An important point requiring discussion is the statistical sensitivity of any study and its capacity to detect the presence of an effect within a population. This is generally referred to as the statistical power of a population sampling study and quantifies the capacity to measure an experimental effect and/or to determine the proportion of the underlying population that show such an effect.

If a population is assumed to be normally distributed with respect to a feature, then only a particular fraction of that population is likely to display such sensitivity above a certain threshold. In the case of possible health effects of wind turbines, the relatively infrequent reports of ill health effects suggest that the sensitive proportion of the population is quite low [100]. The capacity to detect such sensitivity using a population sampling approach will be dependent on the underlying proportion in the population that display such a sensitivity and the number of samples taken from the population. For the Health Canada sleep disturbance study, the smallest detectable percentage of people whose sleep quality was worsened by increased wind turbine noise levels was estimated to be $7 \%$. Since the Health Canada study did not find any significant effects other than annoyance, the number of people suffering from disease due to exposure to wind turbine noise is likely to be substantially less than $7 \%$. For two relatively common clinical conditions of the inner ear, it is estimated that $0.2 \%$ of the population suffer Meniere's disease while recent estimates of superior semicircular canal dehiscence are around $0.1 \%$ of the population. In the absence of a known prevalence in the neighbouring population of diseases caused by wind turbines, the authors have chosen to use $0.1 \%$ of the neighbouring population based on the estimated prevalence of superior semicircular canal dehiscence to demonstrate the difficulty of detecting effects with low levels of prevalence in the population. The authors do not imply that $0.1 \%$ is the actual percentage of the population suffering from diseases caused by wind turbines, since the actual figure is currently unknown.

The committee has used a simple model of statistical power to examine the impact of sample size using the assumptions that (1) the prevalence of the disease is similar to that of semicircular canal dehiscence (i.e. $0.1 \%$ ) and (2) for simplicity we have chosen the best case scenario where the sensitivity of the test for the disease is perfect $(100 \%$ detection and no false alarms).

Figure 1 plots the percentage of studies that would fail to detect the disease with an actual $0.1 \%$ prevalence with sample sizes ranging from 100 to 3200 . The bottom dashed black line indicates 5\%. The above model indicates that (1) for sample sizes of 400 or less there is $70 \%$ to $90 \%$ chance that the test would fail to return a positive result; (2) a sample size of around 3200 samples is needed before there is a less

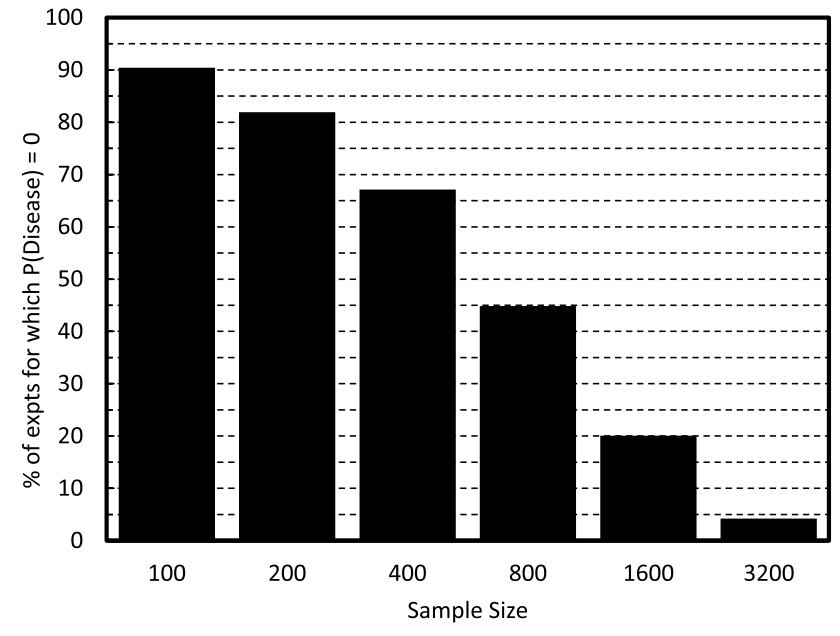

Fig. 1 Percentage of experiments for which the occurrence of the disease is zero. The disease probability is $0.1 \%$ and the sensitivity and specificity are both 1.0

than $5 \%$ chance that the test will provide a type II error (i.e. incorrectly retain a false null hypothesis). In this simulation there was a disease $(0.1 \%$ rate) and the black bars represent the percentage of tests that would return $\mathrm{P}($ disease $)=0$, i.e. a type II error

This indicates that, of the many population studies of the effects wind turbines on the population where the focus has been on random sampling, the numbers of samples (generally of the order $10^{2}$ ) are well below the numbers that would be required to reliably detect the other relatively common inner ear conditions (order $10^{4}$ samples). In the absence of any other data, the disease prevalence is estimated from the prevalence of superior semicircular canal dehiscence (SCD: $0.1 \%$ ). A systematic analysis of health practitioner records as a percentage of the total exposed population in potentially affected regions might provide a more grounded indication of the likely fraction of the population that may be susceptible to wind turbine sound (presuming that is based on some similar inner ear dysfunction).

A second and critical issue in the analysis of such low prevalence occurrences is how they are identified and currently treated in the analysis of the population data. It is statistically impossible for a small number of low prevalence samples to have any meaningful impact on summary statistics (the mean, median or mode) of a population. The meta-analyses of previous studies of potential health effects of wind turbines have also used more traditional summary and linear regression models. More appropriate would be the identification of people who may potentially be more likely to be affect by wind turbine noise for further examination, an approach that is being pursued in the recent NHMRC funded research projects. 
Because many of the symptoms claimed to be caused by wind turbine noise are reasonably common in populations not exposed to wind turbine noise, it is even more difficult to detect statistically significant changes in the occurrence of these symptoms in populations that are exposed to wind turbine noise. The Health Canada study [11] was designed to be able to detect a relationship between a change in sleep disturbance and wind turbine noise level. It was estimated that there would be 1120 survey responses and the standard $95 \%$ confidence limits were to be used. This meant that there was an $80 \%$ chance of being able to detect at least a $7 \%$ difference in sleep disturbances in persons exposed to outdoor wind turbine noise of more than $40 \mathrm{~dB}(\mathrm{~A})$ compared to persons exposed to less than $40 \mathrm{~dB}(\mathrm{~A})$ and only a $5 \%$ chance of detecting a difference where no difference actually existed [11, 104]. This statistical power calculation assumed that the baseline prevalence for reported sleep disturbance in people exposed to outdoor wind turbine noise of less than $40 \mathrm{~dB}(\mathrm{~A})$ was between 7 and $10 \%$ and that $20 \%$ of the survey population would be exposed to outdoor wind turbine noise of more than $40 \mathrm{~dB}(\mathrm{~A})$. It is probable that similar figures would apply to the detection of health effects. This means that if wind turbines cause health problems for less than 7\% of the population, this effect is going to be very difficult, if not impossible, to rigorously detect using these sample sizes. Much larger sample sizes would need to be applied to detect low prevalence effects.

A Danish study [105, 106] currently underway will address some of the problems raised in this section. It is a study of all Danes exposed to wind turbine noise since 1982. It is looking at the potential association of wind turbine noise with diabetes, cardiovascular diseases, perinatal birth factors and the use of medication for hypertension, sleep problems and depression. It includes 553,066 dwellings and more than 1.3 million adult Danes. This study did not support an association between wind turbine noise and redemption of antihypertension medication [107]. Poulsen et al. [108] did find an association between outdoor wind turbine noise level and first redemption of sleep medication or antidepressants by people aged 65 years or older.

\section{References}

1. Commonwealth of Australia.: Senate Select Committee on Wind Turbines Final report, p. 350. Commonwealth of Australia, Canberra (2015)

2. Hübner, G., Pohl, J., Hoen, B., Firestone, J., Rand, J., Elliott, D., Haac, R.: Monitoring annoyance and stress effects of wind turbines on nearby residents: a comparison of U.S. and European samples. Environ. Int. 132(105090), 1-9 (2019). https:// doi.org/10.1016/j.envint.2019.105090

3. Davy, J.L., Burgemeister, K., Hillman, D.: Wind turbine sound limits: current status and recommendations based on mitigating noise annoyance. Appl. Acoust. 140, 288-295 (2018). https:// doi.org/10.1016/j.apacoust.2018.06.009

4. ETSU-R-97.: The Assessment and Rating of Noise from Wind Farms, pp. 1-153. Department of Trade and Industry, London (1996)

5. World Health Organisation: Environmental Noise Guidelines for the European Region. World Health Organisation Regional Office for Europe, Copenhagen (2018)

6. National Health and Medical Research Council.: NHMRC Statement: Evidence on Wind Farms and Human Health, p. 1. National Health and Medical Research Council, Canberra (2015)

7. van den Berg, F.: Criteria for wind farm noise: Lmax and Lden. Paper presented at the Euronoise 2008, Paris, June 29-July 4 (2008)

8. Michaud, D.S., Keith, S.E., Feder, K., Voicescu, S.A., Marro, L., Than, J., Guay, M., Bower, T., Denning, A., Lavigne, E., Whelan, C., Jannssen, S.A., Leroux, T., van den Berg, F.: Personal and situational variables associated with wind turbine noise annoyance. J. Acoust. Soc. Am. 139(3), 1455-1466 (2016). https://doi.org/10.1121/1.4942390

9. Michaud, D.S., Keith, S.E., Feder, K., Voicescu, S.A., Marro, L., Than, J., Guay, M., Bower, T., Denning, A., Lavigne, E., Whelan, C., Jannssen, S.A., Leroux, T., van den Berg, F.: Erratum: Personal and situational variables associated with wind turbine noise annoyance [J. Acoust. Soc. Am. 139(3), 1455-1466 (2016)]. J. Acoust. Soc. Am. 140(4), 2234 (2016). http://dx.doi.org/10.1121/1.4963838

10. Michaud, D.S., Feder, K., Keith, S.E., Voicescu, S.A., Marro, L., Than, J., Guay, M., Denning, A., McGuire, D.A., Bower, T., Lavigne, E., Murray, B.J., Weiss, S.K., van den Berg, F.: Exposure to wind turbine noise: perceptual responses and reported health effects. J. Acoust. Soc. Am. 139(3), 1443-1454 (2016). https://doi.org/10.1121/1.4942391

11. Michaud, D.S., Feder, K., Keith, S.E., Voicescu, S.A., Marro, L., Than, J., Guay, M., Denning, A., Murray, B.J., Weiss, S.K., Villeneuve, P.J., van den Berg, F., Bower, T.: Effects of wind turbine noise on self-reported and objective measures of sleep. Sleep 39(1), 97-109 (2016). https://doi.org/10.5665/sleep.5326

12. Carlile, S., Davy, J.L., Hillman, D., Burgemeister, K.: A review of the possible perceptual and physiological effects of wind turbine noise. Trends Hear. 22, 1-10 (2018). https://doi. org/10.1177/2331216518789551

13. Council of Canadian Academies: Understanding the Evidence: Wind Turbine Noise. The Expert Panel on Wind Turbine Noise and Human Health, Council of Canadian Academies, Ottawa (2015)

14. Hansen, C.H., Hansen, K.L.: Recent advances in wind turbine noise research. Acoustics 2, 172-207 (2020). https://doi. org/10.3390/acoustics2010013

15. Knopper, L.D., Ollson, C.A., McCallum, L.C., Whitfield Aslund, M.L., Berger, R.G., Souweine, K., McDaniel, M.: Wind turbines and human health. Front. Public Health (2014). https://doi.org/10.3389/fpubh.2014.00063

16. L'Agence nationale de sécurité sanitaire de l'alimentation, d.1.e.e.d.t.: Evaluation des effets sanitaires des basses fréquences sonores et infrasons dus aux parcs éoliens [Evaluation of the health effects of low sound and infrasonic frequencies due to wind farms]. In. L'Agence nationale de sécurité sanitaire de l'alimentation, de l'environnement et du travail, Maisons-Alfort, France (2017)

17. McCunney, R.J., Mundt, K.A., Colby, W.D., Dobie, R., Kaliski, K., Blais, M.: Wind turbines and health: a critical review of the scientific literature. J. Occup. Environ. Med. 56(11), e108e130 (2014). https://doi.org/10.1097/JOM.0000000000000313 
18. National Health and Medical Research Council.: Information Paper: Evidence on Wind Farms and Human Health, pp. 1-42. National Health and Medical Research Council, Canberra (2015)

19. Onakpoya, I.J., O'Sullivan, J., Thompson, M.J., Heneghan, C.J.: The effect of wind turbine noise on sleep and quality of life: a systematic review and meta-analysis of observational studies. Environ. Int. 82, 1-9 (2015). https://doi.org/10.1016/j.envin t.2015.04.014

20. Schmidt, J.H., Klokker, M.: Health effects related to wind turbine noise exposure: a systematic review. PLoS ONE 9(12), e114183 (2014). https://doi.org/10.1371/journal.pone.0114183

21. van Kamp, I., van den Berg, F.: Health effects related to wind turbine sound, including low-frequency sound and infrasound. Acoust. Aust. 46(1), 31-57 (2018). https://doi.org/10.1007/s4085 7-017-0115-6

22. Hansen, K.L., Hansen, C.H., Zajamšek, B.: Outdoor to indoor reduction of wind farm noise for rural residences. Build. Environ. 94, 764-772 (2015)

23. Marcillo, O., Arrowsmith, S., Blom, P., Jones, K.: On infrasound generated by wind farms and its propagation in low-altitude tropospheric waveguides. J. Geophys. Res. Atmos. 120(19), 9855-9868 (2015). https://doi.org/10.1002/2014JD022821

24. Pedersen, S., Møller, H., Waye, K.P.: Indoor measurements of noise at low frequencies-problems and solutions. J. Low Freq. Noise Vib. Act. Control 26(4), 249-270 (2007)

25. Schomer, P.D., Erdreich, J., Pamidighantam, P.K., Boyle, J.H.: A theory to explain some physiological effects of the infrasonic emissions at some wind farm sites. J. Acoust. Soc. Am. 137(3), 1356-1365 (2015). https://doi.org/10.1121/1.4913775

26. Zajamšek, B., Hansen, K.L., Doolan, C.J., Hansen, C.H.: Characterisation of wind farm infrasound and low-frequency noise. J. Sound Vib. 370, 176-190 (2016). https://doi.org/10.1016/j. jsv.2016.02.001

27. Zorumski, W., Willshire Jr., W.: Downwind sound propagation in an atmospheric boundary layer. AIAA J. 27(5), 515-523 (1989). https://doi.org/10.2514/3.10141

28. Thorsson, P., Persson Waye, K., Smith, M., Ögren, M., Pedersen, E., Forssén, J.: Low-frequency outdoor indoor noise level difference for wind turbine assessment. J. Acoust. Soc. Am. 143(3), 206-211 (2018). https://doi.org/10.1121/1.5027018

29. Hoffmeyer, D., Jakobsen, J.: Sound insulation of dwellings at low frequencies. J. Low Freq. Noise Vib. Act. Control 29(1), 15-23 (2010)

30. Salt, A.N., Hullar, T.E.: Responses of the ear to low frequency sounds, infrasound and wind turbines. Hear. Res. 268, 12-21 (2010)

31. Salt, A.N., Lichtenhan, J.T.: How does wind turbine noise affect people? Acoust. Today 10, 20-28 (2014)

32. Dommes, E., Bauknecht, H., Scholz, G., Rothemund, Y., Hensel, J., Klingebiel, R.: Auditory cortex stimulation by low-frequency tones-an fMRI study. Brain Res. 1304, 129-137 (2009). https ://doi.org/10.1016/j.brainres.2009.09.089

33. Weichenberger, M., Bauer, M., Kühler, R., Hensel, J., Forlim, C.G., Ihlenfeld, A., Ittermann, B., Gallinat, J., Koch, S., Kühn, S.: Altered cortical and subcortical connectivity due to infrasound administered near the hearing threshold-evidence from fMRI. PLoS ONE 12(4), e0174420 (2017). https://doi. org/10.1371/journal.pone.0174420

34. Weichenberger, M., Kühler, R., Bauer, M., Hensel, J., Brühl, R., Ihlenfeld, A., Ittermann, B., Gallinat, J., Koch, S., Tilmmann, S., Kühn, S.: Brief bursts of infrasound may improve cognitive function-an fMRI study. Hear. Res. 328, 87-93 (2015). https:// doi.org/10.1016/j.heares.2015.08.001

35. Micic, G., Zajamsek, B., Lack, L., Hansen, K., Doolan, C., Hansen, C., Vakulin, A., Lovato, N., Bruck, D., Chai-Coetzer, C.L., Mercer, J., Catchside, P.: A review of the potential impacts of wind farm noise on sleep. Acoust. Aust. 46(1), 87-97 (2018). https://doi.org/10.1007/s40857-017-0120-9

36. van den Berg, F.: Effects of sound on people. In: Bowdler, D., Leventhall, G. (eds.) Wind Turbine Noise, vol. 6, pp. 129-151. Multi-Science Publishing Co.Ltd, Brentwood (2011)

37. Janssen, S., Vos, H., Eisses, A.R.: Hinder door geluid van windturbines-dosis-effectrelaties op basis van Nederlandse en Zweedse gegevens (Annoyance from wind turbine sounddose-effect relations based on Dutch and Swedish data-in Dutch) TNO-rapport 2008-D-R1051/B. In., vol. TNO-rapport 2008-D-R1051/B, pp. 1-29. TNO, Delft (2008)

38. Bakker, R.H., Pedersen, E., van den Berg, G.P., Stewart, R.E., Lok, W., Bouma, J.: Impact of wind turbine sound on annoyance, self-reported sleep disturbance and psychological distress. Sci. Total Environ. 425, 42-51 (2012). https://doi. org/10.1016/j.scitotenv.2012.03.005

39. Pedersen, E.: Health aspects associated with wind turbine noise-results from three field studies. Noise Control Eng. J. 59(1), 47-53 (2011). https://doi.org/10.3397/1.3533898

40. Pedersen, E., Persson Waye, K.: Perception and annoyance due to wind turbine noise: a dose-response relationship. J. Acoust. Soc. Am. 116(6), 3460-3470 (2004)

41. Pedersen, E., van den Berg, F., Bakker, R., Bouma, J.: Response to noise from modern wind farms in The Netherlands. J. Acoust. Soc. Am. 126, 634-643 (2009). https://doi. org/10.1121/1.3160293

42. Pedersen, E., Persson Waye, K.: Wind turbine noise, annoyance and self-reported health and well-being in different living environments. Occup. Environ. Med. 64(7), 480-486 (2007)

43. Feder, K., Michaud, D.S., Keith, S.E., Voicescu, S.A., Marro, L., Than, J., Guay, M., Denning, A., Bower, T., Lavigne, E., Whelan, C., van den Berg, F.: An assessment of quality of life using the WHOQOL-BREF among participants living in the vicinity of wind turbines. Environ. Res. 142, 227-238 (2015). https://doi.org/10.1016/j.envres.2015.06.043

44. Mroczek, B., Banaś, J., Machowska-Szewczyk, M., Kurpas, D.: Evaluation of quality of life of those living near a wind farm. Int. J. Environ. Res. Public Health 12, 6066-6083 (2015). https ://doi.org/10.3390/ijerph120606066

45. Mroczek, B., Kurpas, D., Karakiewicz, B.: Influence of distances between places of residence and wind farms on the quality of life in near by areas. Ann. Agric. Environ. Med. 19(4), 692-696 (2012)

46. Shepherd, D., McBride, D., Welch, D., Dirks, K.N., Hill, E.M., et al.: Evaluating the impact of wind turbine noise on healthrelated quality of life. Noise Health 13(54), 333 (2011)

47. Leventhall, G., Pelmear, P., Benton, S.: A Review of Published Research on Low Frequency Noise and Its Effects. Department for Environment, Food and Rural Affairs, London (2003)

48. Moorhouse, A.T., Waddington, D.C., Adams, M.D.: Procedure for the assessment of low frequency noise complaints. Report for Defra, NANR45 Revision 1. Acoustics Research Centre, University of Salford (2011)

49. International Organization for Standardization: ISO 226:1987 Normal Equal-Loudness Level Contours. International Organization for Standardization, Geneva (1987)

50. Dobie, R.: Robert Dobie's letter regarding Salt and Lichtenham, Letter to the editor. Acoust. Today 10(2), 14 (2014)

51. Leventhall, G.: How the "mythology" of infrasound and low frequency noise related to wind turbines might have developed. Paper Presented at the First International Meeting on Wind Turbine Noise: Perspectives for Control, Berlin, Germany, 17-18 October (2005)

52. Leventhall, G.: Infrasound from wind turbines-fact, fiction or deception. Can. Acoust. 34(2), 29-36 (2006) 
53. Leventhall, G.: Concerns about infrasound from wind turbines. Acoust. Today 9(3), 30-38 (2013)

54. Schomer, P.D.: Comments on recently published article, concerns about infrasound from wind turbines. Acoust. Today 9(4), 7-9 (2013)

55. Jakobsen, J.: Danish guidelines on environmental low frequency noise, infrasound and vibration. J. Low Freq. Noise Vib. Act. Control 20(3), 141-148 (2001). https://doi.org/10.1260/2F026 3092011493091

56. van den Berg, G.P., Passchier-Vermeer, W.: Assessment of low frequency noise complaints. Paper Presented at the Internoise 1999, Fort Lauderdale, 06-08 December 1999

57. Broner, N.: A simple outdoor criterion for assessment of low frequency noise emission. Acoust. Aust. 39(1), 7-14 (2011)

58. Hessler, G.F.: Proposed criteria in residential communities for low-frequency noise emissions from industrial sources. Noise Control Eng. J. 52(4), 179-185 (2004). https://doi. org/10.3397/1.2839748

59. Broner, N., Leventhall, G.: Low frequency noise annoyance assessment by low frequency noise rating (LFNR) curves. J. Low Freq. Noise Vib. 2, 20-28 (1983). https://doi.org/10.1177/02630 9238300200103

60. Inukai, Y., Taya, H., Utsugi, A., Nagamur, N.: A new evaluation method for low frequency noise. Paper presented at the Internoise 90

61. Vercammen, M.L.S.: Setting limits for low frequency noise. J. Low Freq. Noise Vib. 8, 105-109 (1989). https://doi. org/10.1260/2F0263092011493091

62. Vercammen, M.L.S.: Low frequency noise limits. J. Low Freq. Noise Vib. 11, 7-13 (1992). https://doi.org/10.1177/2F02630923 9201100102

63. Evans, T., Cooper, J., Lenchine, V.: Low frequency noise near wind farms and in other environments. Environment Protection Authority, South Australia and Resonate Acoustics, Adelaide (2013)

64. Hansen, K., Zajamsek, B., Hansen, C.: Identification of low frequency wind turbine noise using secondary windscreens of various geometries. Noise Control Eng. J. 62(2), 69-82 (2014)

65. Hansen, K., Zajamsek, B., Hansen, C.: Comparison of the noise levels measured in the vicinity of a wind farm for shutdown and operational conditions. In: INTER-NOISE and NOISE-CON Congress and Conference Proceedings 2014, vol. 2, pp. 51925202. Institute of Noise Control Engineering

66. ANSI/ASA.: ANSI/ASA S12.9-2016/Part 7 American National Standard Quantities and Procedures for Description and Measurement of Environmental Sound, Part 7: Measurement of Lowfrequency Noise and Infrasound Outdoors in the Presence of Wind and Indoors in Occupied Spaces. ANSI/ASA (2016)

67. Crichton, F., Dodd, G., Schmid, G., Gamble, G., Cundy, T., Petrie, K.J.: The power of positive and negative expectations to influence reported symptoms and mood during exposure to wind farm sound. Health Psychol. 33(12), 1588-1592 (2014). https:// doi.org/10.1037/hea0000037

68. Crichton, F., Dodd, G., Schmid, G., Gamble, G., Petrie, K.J.: Can expectations produce symptoms from infrasound associated with wind turbines? Health Psychol. 33(4), 360-364 (2014). https:// doi.org/10.1037/a0031760

69. Tonin, R., Brett, J., Colagiuri, B.: The effect of infrasound and negative expectations to adverse pathological symptoms from wind farms. J. Low Freq. Noise Vib. Act. Control 35(1), 77-90 (2016). https://doi.org/10.1177/0263092316628257

70. Cowan, J.P.: The Kokomo Hum Investigation. Acentech Incorporated, Moulton (2003)

71. Leventhall, G.: Low frequency noise and annoyance. Noise Health 6(23), 59-72 (2004)
72. Mullins, J.H., Kelly, J.P.: The mystery of the Taos hum. Echoes 5(3), 6 (1995)

73. Vasudevan, R.N., Gordon, C.G.: Experimental study of annoyance due to low frequency environmental noise. Appl. Acoust. 10, 57-69 (1977). https://doi.org/10.1016/0003-682X(77)90007 $-\mathrm{X}$

74. Lee, S., Kim, K., Choi, W., Lee, S.: Annoyance caused by amplitude modulation of wind turbine noise. Noise Control Eng. J. 59(1), 38-46 (2011). https://doi.org/10.3397/1.3531797

75. von Hünerbein, S., King, A., Piper, B., Cand, M.: Wind Turbine Amplitude Modulation: Research to Improve Understanding as to its Cause and Effect Work Package B(2): Development of an AM Dose-Response Relationship, pp. 140-265. University of Salford, Acoustics Research Centre, Manchester (2013)

76. Bockstael, A., Dekoninck, L., Can, A., Oldoni, D., De Coensel, B., Botteldooren, D.: Reduction of wind turbine noise annoyance: an operational approach. Acta Acust. United Acust. 98, 392-401 (2012). https://doi.org/10.3813/AAA.918524

77. Ioannidou, C., Santurette, S., Jeong, C.-H.: Effect of modulation depth, frequency, and intermittence on wind turbine noise annoyance. J. Acoust. Soc. Am. 139(3), 1241-1251 (2016). https://doi. org/10.1121/1.4944570

78. Yokoyama, S., Sakamoto, S., Tachibana, H.: Study on the amplitude modulation of wind turbine noise: part 2- Auditory experiments. Paper Presented at the Inter-noise 2013, Innsbruck, Austria

79. Institute of Acoustics United Kingdom.: A Method for Rating Amplitude Modulation in Wind Turbine Noise. Institute of Acoustics United Kingdom (2016)

80. Large, S.: A quantitative and qualitative review of amplitude modulated noise from wind energy development. Paper Presented at the Inter-noise, Hamburg (2016)

81. Hansen, K.L., Nguyen, P., Zajamsek, B., Catcheside, P., Hansen, C.H.: Prevalence of wind farm amplitude modulation at longrange residential locations. J. Sound Vib. 455, 136-149 (2019). https://doi.org/10.1016/j.jsv.2019.05.008

82. Perkins, R.A., Lotinga, M.J., Berry, B., Grimwood, C.J., Stansfeld, S.A.: A review of research into the human response to amplitude-modulated wind turbine noise and development of a planning control method. Paper Presented at the Inter-noise, Hamburg (2016)

83. Wright, J., Perkins, R.A.: Wind Turbine AM Review Phase 1 Report. WSP Parsons Brinckerhoff, Bristol (2015)

84. Lotinga, M.J., Perkins, R.A.: Wind Turbine AM Review Phase 2 Report. WSP Parsons Brinckerhoff, Bristol (2016)

85. Bowdler, D., Cand, M., Hayes, M., Irvine, G.: Wind turbine noise amplitude modulation penalty considerations. Proc. Inst. Acoust. 40(1), 253-261 (2018)

86. Department of Planning and Infrastructure.: Draft NSW Planning Guidelines: Wind Farms, pp. 1-55. Department of Planning and Infrastructure, State of New South Wales, Sydney (2011)

87. Cooper, J., Evans, T., Petersen, D.: Method for assessing tonality at residences near wind farms. Int. J. Aeroacoust. 14(5-6), 903-908 (2015)

88. International Organization for Standardization: AcousticsDescription, Measurement and Assessment of Environmental Noise-Part 2: Determination of Environmental Noise Levels. International Organization for Standardization, Geneva (2007)

89. Pedersen, T.H., Søndergaard, M., B., A.: Objective Method for Assessing the Audibility of Tones in Noise, Joint Nordic MethodVersion 2, Report AV 1952/99. DELTA Acoustics \& Vibration, Hørsholm, Denmark (1999)

90. Hansen, C.H., Doolan, C.J., Hansen, K.L.: Wind Farm Noise: Measurement, Assessment, and Control. Wiley, Chichester (2017) 
91. International Organization for Standardization: ISO/PAS 20065:2016 Acoustics-Objective Method for Assessing the Audibility of Tones in Noise-Engineering Method. International Organization for Standardization, Geneva (2016)

92. International Organization for Standardization: ISO 1996-2:2017 Acoustics-Description, Measurement and Assessment of Environmental Noise-Part 2: Determination of Sound Pressure Levels. International Organization for Standardization, Geneva (2017)

93. Standards New Zealand.: NZS 6808:2010 Acoustics-Wind Farm Noise, pp. 1-43. Standards New Zealand (2010)

94. Rogers, P., Sweetman, G., Burgemeister, K.: Decision of Hearing Commissioners on a Review of Resource Consent Conditions Relating to the Te Rere Hau Wind Farm Operated by New Zealand Windfarms Limited, vol. PGR-120496-5-208-V1, p. 151. Palmerston North City Council (2017)

95. Smith, M., Chiles, S.: Analysis techniques for wind farm sound level measurements. Acoust. Aust. 40(1), 51-56 (2012)

96. South Australian Environment Protection Authority: Wind Farms Environmental Noise Guidelines 2019-Draft for Consultation. South Australian Environment Protection Authority, Adelaide (2019)

97. Søndergaard, L.S., Pedersen, T.H.: Tonality in wind turbine noise. IEC 61400-11 ver. 2.1 and 3.0 and the Danish/joint nordic method compared with listening tests. Paper Presented at the Wind Turbine Noise (2013)

98. Yokoyama, S., Kobayashi, T., Tachibana, H.: Perception of tonal components contained in wind turbine noise. Paper Presented at the Inter-noise 2016, Hamburg (2016)

99. Oliva, D., Hongisto, V., Haapakangas, A.: Annoyance of lowlevel tonal sounds-factors affecting the penalty. Build. Environ. 123, 404-414 (2017)

100. Office of the National Wind Farm Commissioner: 2018 Annual Report by the Office of the National Wind Farm Commissioner to the Parliament of Australia. Office of the National Wind Farm Commissioner, Melbourne (2019)

101. Leventhall, G., Benton, S., Robertson, D.: Coping strategies for low frequency noise. J. Low Freq. Noise Vib. Act. Control 27(1), 35-52 (2008). https://doi.org/10.1260/2F026309208784425460
102. Leventhall, G., Robertson, D., Benton, S., Leventhall, L.: Helping sufferers to cope with noise using distance learning cognitive behaviour therapy. J. Low Freq. Noise Vib. Act. Control 31(3), 193-203 (2012). https://doi.org/10.1260/2F0263-0923.31.3.193

103. van den Berg, F., de Boer, K.: The effect of brown and black noise on persons suffering from a low frequency sound. Paper Presented at the International Congress on Acoustics 2019, Aachen, Germany (2019)

104. Voicescu, S.A., Michaud, D.S., Feder, K., Marro, L., Than, J., Guay, M., Denning, A., Bower, T., van den Berg, F., Broner, N., Lavigne, E.: Estimating annoyance to calculated wind turbine shadow flicker is improved when variables associated with wind turbine noise exposure are considered. J. Acoust. Soc. Am. 139(3), 1480-1492 (2016). https://doi.org/10.1121/1.4942403

105. Poulsen, A.H., Sørensen, M.: Wind turbine noise and health, a nationwide prospective study in Denmark. Paper Presented at the Inter-noise 2016, Hamburg, Germany, 21-24 August (2016)

106. Backalacz, C., Søndergaard, L.S., Laursen, J.E.: "Big noise data" for wind turbines. Paper Presented at the Inter-noise 2016, Hamburg, Germany, 21-24 August (2016)

107. Poulsen, A.H., Raaschou-Nielsen, O., Peña, A., Hahmann, A.N., Nordsborg, R.B., Ketzel, M., Brandt, J., Mette Sørensen, M.: Long-term exposure to wind turbine noise and redemption of antihypertensive medication: a nationwide cohort study. Environ. Int. 121, 207-215 (2018). https://doi.org/10.1016/j.envin t.2018.08.054

108. Poulsen, A.H., Raaschou-Nielsen, O., Peña, A., Hahmann, A.N., Nordsborg, R.B., Ketzel, M., Brandt, J., Sørensen, M.: Impact of long-term exposure to wind turbine noise on redemption of sleep medication and antidepressants: a nationwide cohort study. Environ. Health Perspect. 127(3), 037005 (2019). https://doi. org/10.1289/EHP3909

Publisher's Note Springer Nature remains neutral with regard to jurisdictional claims in published maps and institutional affiliations. 